\title{
Graphite-based solid lubricant for high-temperature lubrication
}

\author{
Wenjuan HUAI, Chenhui ZHANG*, Shizhu WEN \\ State Key Laboratory of Tribology, Tsinghua University, Beijing 100084, China \\ Received: 07 July 2020 / Revised: 08 September 2020 / Accepted: 23 September 2020 \\ (C) The author(s) 2020.
}

\begin{abstract}
High-temperature solid lubricants play a significant role in the hot metal forming process. However, preparing high-temperature solid lubricant is formidably challenging due to the stern working conditions. Here we successfully develop a new type of eco-friendly high-temperature graphite-based solid lubricant by using amorphous silica dioxide, aluminum dihydrogen phosphate, and solid lubricant graphite. The solid lubricating coating exhibits excellent tribological properties with a very low friction coefficient and good wear protection for workpiece at high temperature under the air atmosphere. An array of analytical techniques reveals the existence of solid lubricant graphite in the lubricating coating after the high-temperature friction test. A synergistic effect between the protective surface film and the solid lubricant graphite is proposed to account for such superior lubricating performance. This work highlights the synergistic effect between the protection layer and the lubricant graphite and further provides the insight in designing the high-temperature solid lubricant.
\end{abstract}

Keywords: graphite-based solid lubricant coating; high temperature; air atmosphere; high lubricating performance

\section{Introduction}

Metal forming is vital to manufacturing metals into various shapes for different applications. Among factors affecting the metal forming process, the friction between the metal and the mold plays a critical role. Friction determines the required force and, thereby, the energy needed to influence the intended changes of the shape through the bulk deformation of the workpiece. It also affects the stress and strain distribution and, hence, the quality of the final product. Generally, friction in metal forming processes is complicated as it depends on many variables. Among those variables, the lubricant is one of the critical parameters, which have been widely employed not only to reduce the friction and wear of workpiece and forming tools but also to promote the flow of metal and to aid the release of the finished parts [1-3]. During the hot metal forming processes, however, conventional lubricants like oil-based lubricants do not work since they would burn when they reach the surface of the hot material. Therefore, solid-lubricating materials with a low friction coefficient and high wear resistance, as well as high efficiency and long durability over a relatively high temperature are required $[4,5]$.

High-temperature solid lubrication, although known for centuries, remains one of the formidable challenges encountered in the tribology field due to the difficulty in designing novel lubricating base materials $[6,7]$. So far, graphite, molybdenum disulfide $\left(\mathrm{MoS}_{2}\right)$, and polytetrafluoroethylene (PTFE) are the conventional, and predominant base lubricants with the highest cost efficiency [8]. Among them, graphite is most widely employed due to the relatively better lubricant performance resulted from the easy sliding behavior associated with weak Van der Waals bonds between layers and from its highly stable structure due to

* Corresponding author: Chenhui ZHANG, E-mail: chzhang@tsinghua.edu.cn 
the strong covalent bond within the layer, as well as its self-lubricating and dry lubricating properties [8-11]. Besides, its high thermal conductivity further facilitates its widespread application in hightemperature processing procedures [12]. In spite of the aforementioned advantages in the lubricating field, however, graphite is inferior in oxygen resistance at the elevated temperature in the ambient atmosphere [13-15]. Specifically, graphite is easily oxidized to carbon monoxide (CO) beyond $400{ }^{\circ} \mathrm{C}$ and carbon dioxide $\left(\mathrm{CO}_{2}\right)$ above $500{ }^{\circ} \mathrm{C}$. Even worse, graphite is seriously degraded to form $\mathrm{CO}_{2}$ beyond $700{ }^{\circ} \mathrm{C}$ [16-18]. Therefore, those deteriorating reactions lead to a reduction in the shearing strength of graphite and a corresponding increase in pore volume and permeability. The resulting rise in the porosity would accelerate the oxidation of graphite due to the increased contact with oxygen. In addition, the removal of $\mathrm{CO}$ and $\mathrm{CO}_{2}$ from the surface could further promote the oxidation reaction and the burnout of graphite [19]. Given those detrimental factors, graphite has been mainly employed as a lubricant for medium-temperature metal forming processes like casting [20], forging [21, 22], and extrusion [23], etc. In contrast to the mediumtemperature application, however, the excellent lubrication performance and economic efficiency also enable the potential utilization of graphite at higher temperature lubricant fields, which otherwise requires a significant improvement of the poor oxygen resistance. In order to ameliorate the oxygen resistance behavior, therefore, extensive research has been performed to establish fundamentals in stabilizing the graphite at high temperatures [24-29]. So far, various approaches have been proposed to realize this improvement by depositing anti-oxidation ceramic coatings on graphite substrate via complicated and costly methods, like pack concentration, plasma spraying, slurry-sintering, low-pressure chemical vapor deposition, and hydrothermal electrophoretic deposition. Many specific examples have been reported such as deposition of multilayer coating, the formation of glass-type or metallic coating subjected to chemical transformations via thermal treatment, and impregnation of glass-forming compounds [30].

The deposition coating could provide a protective barrier blocking the direct contact of carbon with environmental oxygen, especially at high temperatures. The reported compounds used for the protective coating include refraction metals such as $\mathrm{W}, \mathrm{Re}$, $\mathrm{Mo}, \mathrm{Nb}, \mathrm{Hf}, \mathrm{Ti}, \mathrm{Zr}$, their oxides, silicides, borides, carbides, nitrides, and the corresponding composites [24, 30, 31]. Among them, SiC [32] and $\mathrm{MoSi}_{2}$ [33] are the most efficient against high-temperature oxidation due to the formation of a silicon dioxide $\left(\mathrm{SiO}_{2}\right)$-based gas-impermeable oxide film during high-temperature processing. Theoretically, such coating can protect the carbon-based material against oxidation in the air up to $1,800{ }^{\circ} \mathrm{C}$ beyond which the protective film undergoes a failure of fracture. Despite its effective protection at such high temperatures, the performance within the temperature range between 800 and $1,200{ }^{\circ} \mathrm{C}$ is unsatisfactory due to the defects like cracks and holes generated during the preparation process or cooling stage. Those formed defects could not be healed at this temperature range because of the high viscosity of the $\mathrm{SiO}_{2}$-based layer. The unhealed defects could provide further channels for oxygen diffusion, leading to the oxidation of carbon substrate and the subsequent deterioration of the lubrication behavior [34]. It is well known that the temperature range of $800-1,200{ }^{\circ} \mathrm{C}$ is the most common in industrial fields, which necessitates the design of solid lubricants demonstrating better lubrication performance within this temperature window.

In this work, we choose the unmodified graphite as the base lubricant, amorphous $\mathrm{SiO}_{2}$ as the protective filler, and aluminum dihydrogen phosphate $\left(\mathrm{Al}\left(\mathrm{H}_{2} \mathrm{PO}_{4}\right)_{3}\right)$ as the binder and mix them homogeneously in the water to prepare graphite-based solid lubricating coatings at the room temperature. The prepared coating exhibited superior lubricant behavior with a very low coefficient of friction (COF) and high wear resistance, as well as the absence of environmentally hazardous compounds at high temperatures even under ambient conditions. The evaluation via various analytical techniques like micro-Raman, X-ray diffraction (XRD), thermogravimetry-Fourier transform infrared spectroscopy (TG-FTIR) and scanning electron microscopy (SEM) illustrates the protective effect of the composite coating for the interior graphite against its oxidation, thus enabling the superior lubricating performance. 


\section{Experimental}

\subsection{Preparation of the solid lubricating coating}

Amorphous $\mathrm{SiO}_{2}$ was prepared via the precipitation method with sodium silicate and acid as raw materials, and surfactant dodecyltrimethylammonium bromide $(\mathrm{CTAB})$ as a template, and ethanol aqueous solution as a solvent. The mixture underwent reactions at about $50{ }^{\circ} \mathrm{C}$, and then the precursor was centrifuged, washed, dried, and finally sintered in a muffle furnace at an appropriate temperature. After cooling to room temperature naturally, the amorphous $\mathrm{SiO}_{2}$ could be obtained. The as-synthesized $\mathrm{SiO}_{2}$ then was used as a protective filler, without further treatment, to prepare solid lubricating coatings.

The flake graphite with an average size of 10-30 $\mu \mathrm{m}$ (Sinopharm Group) and inorganic powder aluminum dihydrogenphosphate $\left(\mathrm{Al}\left(\mathrm{H}_{2} \mathrm{PO}_{4}\right)_{3}\right)$ (Aladdin) was employed as a base lubricant and binder, respectively, without any further treatment from the purchase. The composite lubricant was prepared from the homogeneous mixture of graphite, amorphous $\mathrm{SiO}_{2}$, binder, and water under an appropriate mass ratio. The as-prepared slurries were then ready for the coating preparation.

A titanium alloy (TC4) disc with a radius of $25.07 \mathrm{~mm}$ and a thickness of $6.0 \mathrm{~mm}$ were employed as the substrate of the lubricant coating. Before coated, the disc was cleaned and polished and then ultrasonically cleaned by acetone and ethanol successively with each for $10 \mathrm{~min}$ to remove the pollutants on the substrate. Then, about 20 drops of the slurries were brushed onto the surface of the cleaned friction counterparts, followed by drying in the oven under $70{ }^{\circ} \mathrm{C}$ for around $2 \mathrm{~h}$. Then the composite coatings bonded to the metal surface were formed with a thickness of $80-120 \mu \mathrm{m}$. The well-prepared coated discs were employed in subsequent friction tests.

\subsection{Friction tests}

High-temperature ball-on-disc tests were carried out by RTEC Tribolab Equipment under the air atmosphere. The heating processes proceeded as follows: the disc sample was automatically heated from room temperature to various target temperatures
(700, 800, and $900{ }^{\circ} \mathrm{C}$ ), and then kept at each target temperature for $30 \mathrm{~min}$. Then the friction experiment started simultaneously with the onset of the loading. The silicon nitride $\left(\mathrm{Si}_{3} \mathrm{~N}_{4}\right)$ ball $(9.525 \mathrm{~mm}$ in diameter) was chosen to slide rotationally with a radius of 17 $\mathrm{mm}$ against the solid lubricating coating on the TC4 disc, and a normal loading of $100 \mathrm{~N}$, and three different sliding speeds (60 mm/s (or $34 \mathrm{rpm}), 90 \mathrm{~mm} / \mathrm{s}$ (or $51 \mathrm{rpm}$ ) and $120 \mathrm{~mm} / \mathrm{s}$ (or $68 \mathrm{rpm}$ )). For each test, the sliding duration was $300 \mathrm{~s}$. The obtained COF of silicon nitride $\left(\mathrm{Si}_{3} \mathrm{~N}_{4}\right)$ ball against coated $\mathrm{TC} 4$ disks were recorded automatically. After cooling to room temperature naturally, the samples were taken out for the following characterization otherwise mentioned specifically. All the tests were reproduced at least three times for each condition to confirm the reproducibility of the results.

\subsection{Characterization}

The phase evaluation was accomplished by powder XRD (pXRD) patterns collected by scanning from $10^{\circ}$ to $90^{\circ}(2 \theta)$, using a step size of $0.02^{\circ}$, at a rate of $2.0\left(^{\circ}\right) / \mathrm{min} 2 \theta$, in a Bruker D8 Advance diffractometer operating at $40 \mathrm{kV}$ and $40 \mathrm{~mA}$ with $\mathrm{Cu} \mathrm{K} \alpha$ radiation ( $\lambda=1.5418 \AA$ ). The thermal stability of the lubricating coating and the corresponding released gas was assessed by TG-FTIR with a joint analysis system consisting of a Thermogravimetric Analyzer (TGA, Netzsch STA 449F3) and a Fourier transform infrared spectroscopy (FTIR, Bruker VERTEX70v). During the experiment, the gases were transferred into the FTIR-gas cell of the Bruker TGA-IR Accessory Unit equipped with a detector via a heated stainless steel transfer line held at $200{ }^{\circ} \mathrm{C}$. FTIR spectra were collected every $30 \mathrm{~s}$ in the wavenumber range between 4000 to $650 \mathrm{~cm}^{-1}$. The morphology of the surface and the elemental distribution within the coating were obtained using a Quanta200 SEM equipped with an energy dispersive X-ray spectrometer (EDS). The local chemical structure of the wear track after the tribological test was studied by a Raman spectroscopy (Horiba JobinYvon HR800) with an $\mathrm{Ar}^{+}$laser wavelength of $532 \mathrm{~nm}$. The cross-section specimens used for the SEM study were prepared by using a line cutting machine firstly. Then the cut sample was mounted in epoxy resin. After the curing of the resin, the 
mounted sample was ground as well as polished to refine the surface so that it can meet the requirements of the SEM test.

\section{Results and discussion}

In order to investigate the tribological behavior of the solid lubricating coating at different sliding speeds, the friction test was conducted with different sliding speeds under the same temperature of $900{ }^{\circ} \mathrm{C}$ (Fig. 1(a)). The COF profile can be generally divided into two parts: the running-in period and the steady period. During the running-in period, the COF fluctuated heavily due to the intensive deformation at the contact interface, while the COF remained relatively stable in the steady period since a dynamic balance was reached with a stable coating formed at the interfacial area. The COF of all different sliding speeds diminished sharply from the high initial value of around 0.43 to $\sim 0.10$ in a few seconds. Then, COF remained around 0.10 during the initial run-in period with different time span. Finally, the COF decreased to a relatively steady and smaller value for the rest testing process with less than 0.08 at $60 / 120 \mathrm{~mm} / \mathrm{s}$ and 0.05 at $90 \mathrm{~mm} / \mathrm{s}$ (Fig. 1(a)). The average friction coefficients at different sliding speeds obtained via the accessory software of the RTEC Tribolab Equipment were tabulated in Table 1. It is noticeable that the average friction coefficients were small in spite of the different speeds, reflecting the prepared lubricating coating could be used within a wide sliding speed range. In addition, the operational temperature is vital for the tribological properties. Therefore, the tribological behavior at different temperatures was also investigated (Fig. 1(b)). It is obviously seen that the COF plots for the experiments at 700 and $800{ }^{\circ} \mathrm{C}$ displayed a similar evolutionary trend, yet with a much smaller starting value of $\sim 0.23$. Moreover, the COF profiles were even smoother with values smaller than 0.05 after the initial run-in process, reflecting a better lubricating performance at 700 and $800^{\circ} \mathrm{C}$ (Fig. 1(b)), which was further confirmed by the calculated average friction coefficients of 0.0511 and 0.0411 at 700 and $800{ }^{\circ} \mathrm{C}$, respectively, under the sliding speed of $90 \mathrm{~mm} / \mathrm{s}$ (Table 1). This behavior could be related to the amount of the remaining graphite owing to the graphite loss derived from its vigorous oxidation under air condition at elevated temperature. With the increase of temperature, an accelerated loss of the graphite resulted in a large decrease in the lubricity property of the prepared coating and a more pronounced fluctuation of the COF curve. Therefore, the operating temperature has a significant effect on the lubricating behavior relative to the sliding speed. Given all components in the lubricating coating, this distinguished tribological performance exhibited by the prepared solid lubricating coating was proposed to be due to the presence of the graphite, which would be discussed later. Altogether, the prepared solid lubricating coating has the potential as a lubricant for practical application in the metal forming field.

In order to explore the adhesion of the coating to the substrate, the images of the specimens at different states were compared (Fig. 2). It can be clearly observed that the coating was well bonded
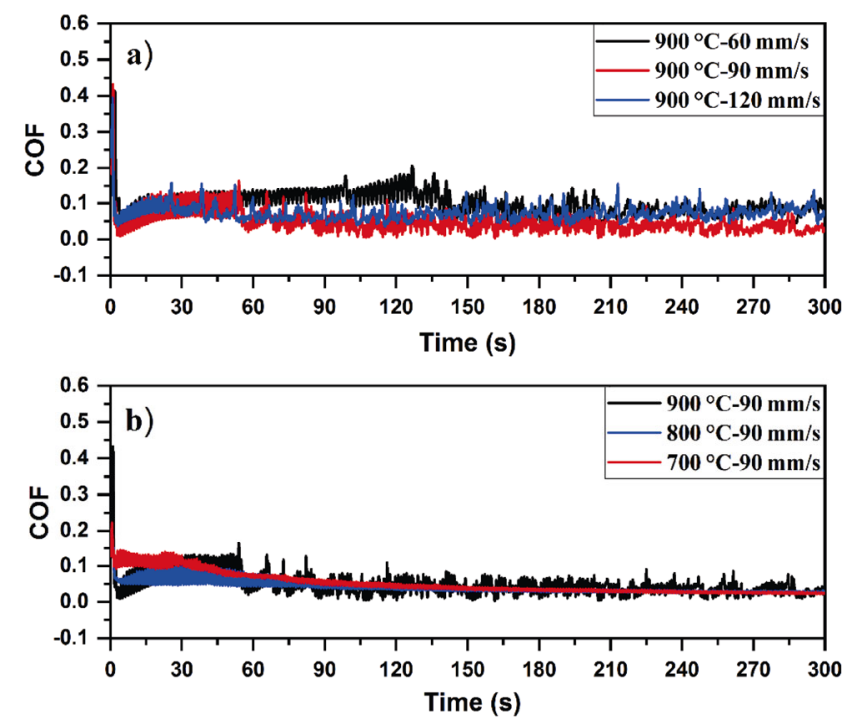

Fig. 1 COF profiles for the prepared solid lubricating coating at (a) $900{ }^{\circ} \mathrm{C}$ with different sliding speeds and (b) different temperatures under the same sliding speed of $90 \mathrm{~mm} / \mathrm{s}$.

Table 1 Average friction coefficients under different friction tests.

\begin{tabular}{ccc}
\hline $\begin{array}{c}\text { Testing } \\
\text { temperature }\left({ }^{\circ} \mathrm{C}\right)\end{array}$ & $\begin{array}{c}\text { Sliding speed } \\
(\mathrm{mm} / \mathrm{s})\end{array}$ & Average COF \\
\hline 700 & 90 & 0.0511 \\
800 & 90 & 0.0411 \\
\hline \multirow{2}{*}{900} & 60 & 0.0993 \\
& 90 & 0.0482 \\
& 120 & 0.0726 \\
\hline
\end{tabular}




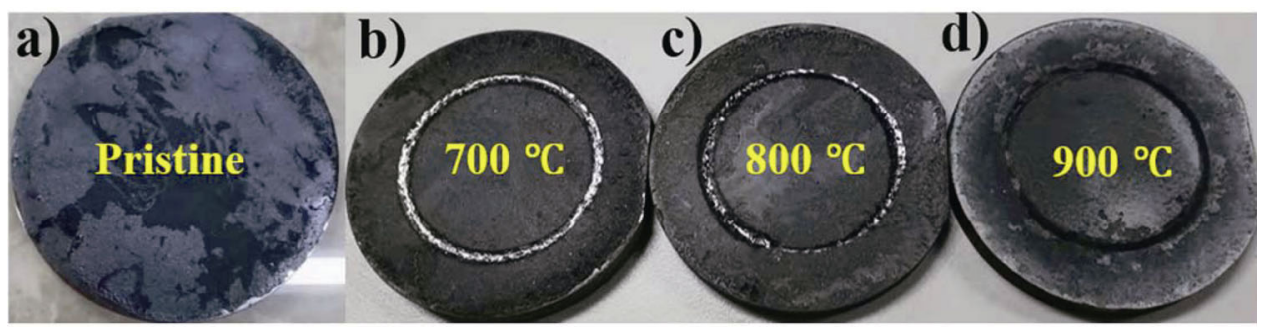

Fig. 2 Images of the prepared solid lubricating coating (a) at the pristine state and (b-d) cooling to the room temperature after the friction tests at different high-temperatures.

to the TC4 disc based on the integrity of the coating on the pristine sample. After the friction test with the sample cooling down from 900 to about $200{ }^{\circ} \mathrm{C}$, the coating was still well bonded to the substrate (Fig. S1(a) in the Electronic Supplementary Material (ESM). When the sample was at room temperature, however, part of it began to crack and finally peeled off from the substrate (Fig. S1(b)). In contrast, the coating remained complete except for the appearance of the wear tracks after friction tests at 700 and $800{ }^{\circ} \mathrm{C}$ as shown in Figs. 2(b) and 2(c). In addition, the wear tracks showed much more brightness of the metallic luster of samples tested at 700 and $800{ }^{\circ} \mathrm{C}$, which will be discussed in the following section. Herein, the sample tested at $900{ }^{\circ} \mathrm{C}$ and $120 \mathrm{~mm} / \mathrm{s}$ was selected as a representative to investigate in-depth due to good triboloical properties at such a harsh condition in comparison with those at 700 and $800{ }^{\circ} \mathrm{C}$ temperature.

As discussed above, the low COF is possibly ascribed to be the presence of the graphite. In order to validate the existence of the graphite in the wear track of the solid lubricating coating after the high-temperature friction test, hence, the micro-Raman spectroscopy was employed (Figs. 3 and S2). In general, the microRaman spectroscopy is used as one of the most powerful and distinguished techniques to evaluate the structural and electronic properties of graphite $[35,36]$. The information on the typical peaks could provide valuable hints to identify the existence of the graphite. Herein, the Raman spectrum of the pristine coating was first measured and then used for comparison. The observed peaks centered at $1,355,1,581,1,623$, and $2,710 \mathrm{~cm}^{-1}$ correspond to the disorder-induced D band, characteristic $G$ band, defect-related $\mathrm{D}^{\prime}$ band, and the second-order 2D band of the graphite, respectively $[37,38]$, which is consistent with the presence of the graphite in the pristine coating. In comparison with the pristine coating, the similar Raman spectra of wear tracks after the friction test at $700 / 800{ }^{\circ} \mathrm{C}$ (Fig. S2) and $900{ }^{\circ} \mathrm{C}$ (Fig. 3(b)) unambiguously demonstrated the existence of the graphite in the wear track after the friction test at high temperature.

In order to assess the phase compositions in the solid lubricating coating, pXRD profiles of the well ground powder sample partially peeled off from the coating after the friction test at $900{ }^{\circ} \mathrm{C}$, as well as the amorphous $\mathrm{SiO}_{2}$, the references were collected (Fig. 4). The comparison of pXRD patterns between the powder of the coating and $\mathrm{SiO}_{2}$ precursor, the references revealed that graphite and amorphous $\mathrm{SiO}_{2}$ were the dominant components of the powder

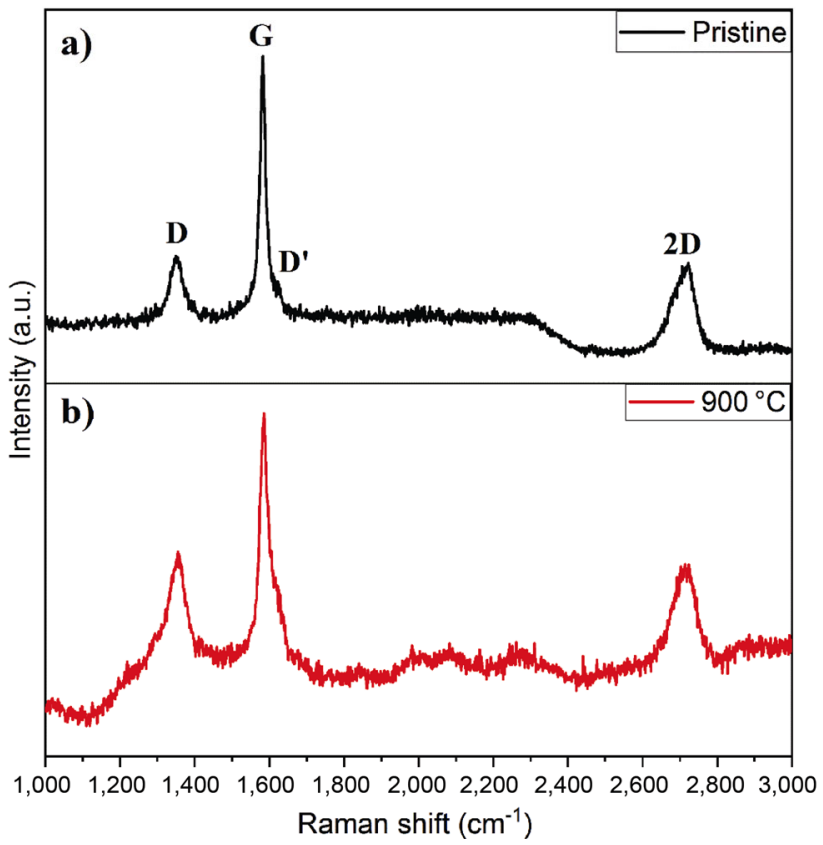

Fig. 3 Micro-Raman spectra of (a) the pristine coating and (b) the wear track of the coating cooling to room temperature after the friction test at $900{ }^{\circ} \mathrm{C}$. 


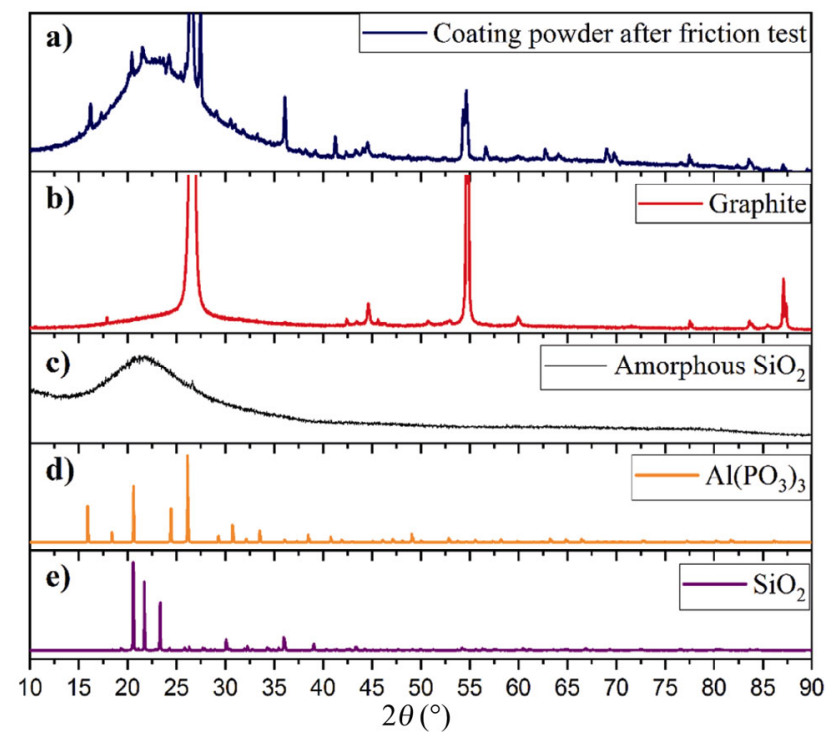

Fig. 4 pXRD patterns of (a) the powder peeled off from the coating after the friction test at $900{ }^{\circ} \mathrm{C}$, (b) pristine graphite and (c) amorphous $\mathrm{SiO}_{2}$, and (d) the reference compound $\mathrm{Al}\left(\mathrm{PO}_{3}\right)_{3}$ (JCPDS card \#13-0430) and (e) the reference compound $\mathrm{SiO}_{2}$ (JCPDS card \#18-1170).

of the coating, which had been heated and tested at $900{ }^{\circ} \mathrm{C}$ for more than $35 \mathrm{~min}$, indicating the reservation of graphite after the friction test at high temperature under the air atmosphere. The remaining of the graphite after the friction test was consistent with the micro-Raman spectrum of the wear track after the $900{ }^{\circ} \mathrm{C}$ friction test. In comparison with the pXRD patterns of $\mathrm{Al}\left(\mathrm{PO}_{3}\right)_{3}$, a few identified peaks belonging to $\mathrm{Al}\left(\mathrm{PO}_{3}\right)_{3}$ in the pXRD patterns of the coating powder were ascribed to the thermal decomposition of $\mathrm{Al}\left(\mathrm{H}_{2} \mathrm{PO}_{4}\right)_{3}$ binder at high temperature. In addition, a series of small fingerprints of crystal $\mathrm{SiO}_{2}$ were also observed by comparing $\mathrm{pXRD}$ patterns in Fig. 4(a) with those in Fig. 4(e), which may be due to the presence of a phase transition between amorphous and crystal $\mathrm{SiO}_{2}$ at elevated temperature in air.
Hence, it was proposed that there existed a potential synergistic effect, which protected graphite against oxidation and enabled the excellent tribological performance under air at the elevated temperature over $700{ }^{\circ} \mathrm{C}$.

To evaluate that protective effect on graphite at high temperature, a comparative test was carried out where a solid lubricating coating composed of graphite and $\mathrm{Al}\left(\mathrm{H}_{2} \mathrm{PO}_{4}\right)_{3}$ was prepared under the same condition as the coating comprising graphite, amorphous $\mathrm{SiO}_{2}$, and $\mathrm{Al}\left(\mathrm{H}_{2} \mathrm{PO}_{4}\right)_{3}$. Both as-prepared coatings were heated to $900{ }^{\circ} \mathrm{C}$ from room temperature within $37 \mathrm{~min}$ in the same muffle furnace and kept at $900{ }^{\circ} \mathrm{C}$ for $30 \mathrm{~min}$, and afterwards the heating process was automatically switched off and the samples naturally cooled to the room temperature. Figure 5 demonstrates the images of two samples after the heating process. It should be noted that the color of $\mathrm{SiO}_{2}$ and $\mathrm{Al}\left(\mathrm{H}_{2} \mathrm{PO}_{4}\right)_{3}$ reactants were white while the graphite was black.

Obviously, the appearance of the surface of those two comparative coating samples was a significant difference. For sample, its color was still black same as the pristine graphite and an array of particles with metallic luster could be observed when the top surface of the coating was peeled off, reflecting the presence of graphite even after the high-temperature treatment. With respect to the sample $b$, the corresponding color was completely changed into white with the appearance of a series of different humps on the surface after the heating treatment (Fig. 5(b)), which could be owing to the formation of the gases derived from the graphite oxidation. The comparison was strongly supported the speculation that the synthesized amorphous $\mathrm{SiO}_{2}$ could well protect the solid lubricant graphite from being oxidized under

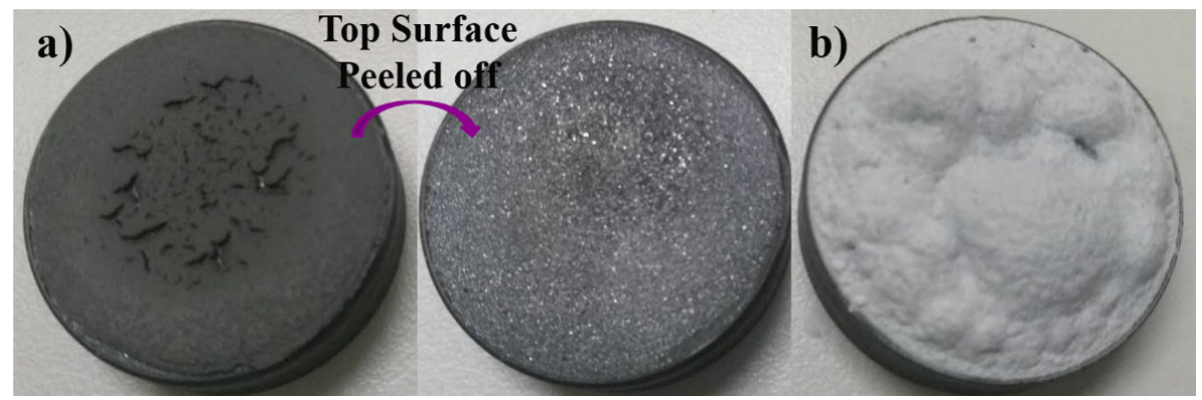

Fig. 5 Images of coating samples prepared with different components after the heating treatment. (a) The coating was composed of graphite, amorphous $\mathrm{SiO}_{2}$, and $\mathrm{Al}\left(\mathrm{H}_{2} \mathrm{PO}_{4}\right)_{3}$ binder. (b) The coating comprised graphite and $\mathrm{Al}\left(\mathrm{H}_{2} \mathrm{PO}_{4}\right)_{3}$ binder. 
the experiment conditions, whereas the $\mathrm{Al}\left(\mathrm{H}_{2} \mathrm{PO}_{4}\right)_{3}$ binder and its decomposition cannot protect the graphite.

The thermal stability plays a vital role in the lubricant application. Hence, the thermal property of the as-prepared coating and pristine graphite was evaluated under the air atmosphere by a cumulative TG-FTIR probe (Fig. 6). It was obviously seen that the TGA results exhibited two completely different curves, reflecting a distinct variation in the mass loss of those two samples with the temperature increase. For the raw graphite (the black line in Fig. 6(a)), it experienced two stages during the entire process. During the first stage, the TGA curve was relatively smooth with a minor mass loss of around $1 \%$ before $600{ }^{\circ} \mathrm{C}$. When it comes to the second stage between 600 and $900{ }^{\circ} \mathrm{C}$, however, the weight loss became pronounced, and even steeper beyond $700{ }^{\circ} \mathrm{C}$. Numerically, the total loss of mass was about $36 \%$ in the second stage. In contrast, the TGA curve of the as-prepared coating was distinctive from the graphite one. Similarly, the curve could also be divided into two parts (the purple line in Fig. 6(a)). The curve showed a sharp mass reduction below $300{ }^{\circ} \mathrm{C}$ with a mass loss of approximately $15 \%$. Whereas the curve became smoother, relative to the first stage, with a mass loss of less than $6 \%$ within the second step of 300-900 ${ }^{\circ} \mathrm{C}$. Generally, the thermal behavior within a high-temperature range, such as $600-900{ }^{\circ} \mathrm{C}$ in this study, is of our primary interest. Compared with the dramatic mass loss of the pure graphite within $600-900{ }^{\circ} \mathrm{C}$, the as-prepared coating only underwent a mass loss of less than $2 \%$, which is 18 times less than that of the pristine graphite. Based on the aforementioned results, therefore, it highlights that the coating prepared in this work could provide an effective avenue in ameliorating the hightemperature lubricating performance of graphite.

In order to qualitatively assess the lost materials with the increasing temperature, in situ FTIR spectra were collected simultaneously with the TGA experiment. The representative data were plotted in Figs. 6(b)-6(d) and S2-S4. The evolved gases at different temperatures were identified by their characteristic absorbance fingerprints, as exhibited in Table 2 where the gas species and their corresponding functional groups were listed. The peaks within 4,000-3,500 $\mathrm{cm}^{-1}$ and 2,000-1,300 $\mathrm{cm}^{-1}$ (Figs. 6(b) and 6(c)) were represented the stretching and bending vibration absorption of $\mathrm{O}-\mathrm{H}$, respectively,

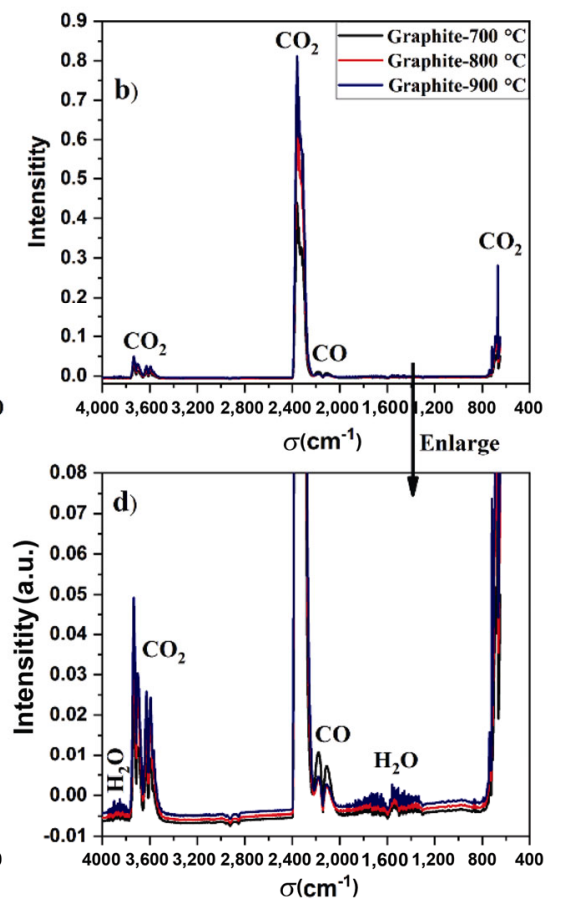

Fig. 6 TG-FTIR analysis. (a) Thermogravimetric curves of the pure pristine and as-prepared composite coating. TFIR spectra of the evolved gases collected in situ from (b) the pristine graphite and (c) the prepared coating at different temperatures. (d) The enlarged one of the spectrum (b) for more clarity. 
Table 2 Evolved gas species and the corresponding functional groups identified using FTIR spectra.

\begin{tabular}{cccc}
\hline Wavenumber $\left(\mathrm{cm}^{-1}\right)$ & Functional group & Vibration & Species \\
\hline $4,000-3,500,2,000-1,300$ & $\mathrm{O}-\mathrm{H}$ & Stretch, bending & $\mathrm{H}_{2} \mathrm{O}$ \\
$2,400-2,220,680-650,3,760-3,500$ & $\mathrm{C}=\mathrm{O}$ & Stretch, bending combination bands & $\mathrm{CO}_{2}$ \\
$2,220-2,030$ & $\mathrm{C}-\mathrm{O}$ & Stretch & $\mathrm{CO}$ \\
\hline
\end{tabular}

indicating the existence of water $\left(\mathrm{H}_{2} \mathrm{O}\right)$ [39-41]. The peaks in the range of 2,400-2,220 $\mathrm{cm}^{-1}$ and 680-650 $\mathrm{cm}^{-1}$ (Figs. 6(b) and 6(c)) stood for the respective stretching and bending vibration of $\mathrm{C}=\mathrm{O}$, implying the presence of carbon dioxide $\left(\mathrm{CO}_{2}\right)[39$, 42]. In comparison with the $\mathrm{CO}_{2}$-related features, especially the peak shapes, in the range of 3,760-3,500 $\mathrm{cm}^{-1}$ in Fig. 6(b) and the enlarged Fig. 6(d), the indistinguishable $\mathrm{CO}_{2}$-related peaks within this range in Fig. 6(c) could be buried by the intensive $\mathrm{H}_{2} \mathrm{O}$-associated features [43]. The zoom-in part of Fig. 6(b) displayed small peaks between 2,220 and $2,030 \mathrm{~cm}^{-1}$ (Fig. 6(d)), which stood for the stretching vibration of $\mathrm{C} \equiv \mathrm{O}$, reflecting the formation of carbon monoxide (CO) during the heating treatment [44].

For the pure graphite, the intensity of both $\mathrm{H}_{2} \mathrm{O}-$ and $\mathrm{CO}_{2}$-based peaks within the range of $100-500{ }^{\circ} \mathrm{C}$ was relatively small (Fig. S3(a)). The appearance of CO-related peaks suggests increased oxidation of graphite. When the temperature rose to $600{ }^{\circ} \mathrm{C}$, the intensity of $\mathrm{CO}_{2}$-related peaks increased but was still very low (Fig. S3(b)), implying enhanced oxidation of the graphite with temperature, while the $\mathrm{H}_{2} \mathrm{O}$-related peak intensity remained. In addition, the intensity of CO-related peaks also increased, further reflecting the increased oxidation of graphite. The variation of the peak intensity below $600{ }^{\circ} \mathrm{C}$ indicates a small mass loss, consistent with the observed TGA result. However, the intensity of $\mathrm{CO}_{2}$-related peaks, especially the ones in the range of 2,400-2,220 $\mathrm{cm}^{-1}$, augmented dramatically with the temperature increase (Fig. 6(b)) while the $\mathrm{H}_{2} \mathrm{O}$ related peak intensity remained almost constant, suggesting a large increase of the graphite oxidation, consistent with the sharp mass loss demonstrated by the TGA curve. Therefore, the minor mass loss of the pure graphite at the first stage below $600{ }^{\circ} \mathrm{C}$ was due to the volatilization of surface water and bound water and $\mathrm{CO}_{2}$ release, while the large mass loss of the pure graphite was largely related to the release of gas species with the dominant components of $\mathrm{CO}_{2}$ and $\mathrm{CO}$ derived from the oxidation of graphite under the air at a high temperature beyond $600{ }^{\circ} \mathrm{C}$.

In terms of the as-prepared coating, $\mathrm{H}_{2} \mathrm{O}$-based peak intensity increased more pronounced, relative to that of $\mathrm{CO}_{2}$-relative peak, with temperature increasing from 100 to $300{ }^{\circ} \mathrm{C}$ (Fig. S4), reflecting an increased mass loss due to the predominant $\mathrm{H}_{2} \mathrm{O}$ loss, in good agreement with sharp sloping TGA curve. Whereas the intensity of peaks associated with $\mathrm{CO}_{2}$ increased but with a relatively slower rate and the peak intensity pertaining to $\mathrm{H}_{2} \mathrm{O}$ varied little in the temperature range of $400-900{ }^{\circ} \mathrm{C}$ (Figs. S5 and 6(c)), indicating a smaller mass loss rate. In addition, the peak intensity of the coating was much lower than that of the pure graphite, reflecting a much smaller mass loss for the coating at high temperature, consistent with the variation in TGA curves. Moreover, the absence of CO-related peaks further implied a less severe oxidation of graphite than the pure graphite. Hence, the sharp weight loss up to $300{ }^{\circ} \mathrm{C}$ could be unambiguously attributed to the solvent water vaporization and the desorbed $\mathrm{CO}_{2}$, while the slow mass loss in the temperature scope of $300-900{ }^{\circ} \mathrm{C}$ was attributed to the same released gas species as those in the first step except a little bit increase of $\mathrm{CO}_{2}$ because of the enhanced graphite oxidation driven by the elevated temperature.

Altogether, the above analysis in the mass loss demonstrated better thermal stability of the coating, which was ascribed to the inhibited oxidation of graphite at high temperatures. This is also in accordance with the excellent tribological behavior of the asprepared coating at high temperatures.

In order to explore the morphology of the surface, SEM images of the wear track at different lubricating coating regions on the disc after the friction test were collected (Fig. 7). Although the disc was continuously covered by the prepared coating throughout the whole experiment, part of the top surface would 
crumble off when the temperature was below $200{ }^{\circ} \mathrm{C}$ after the cooling process, as described above (Fig. S1). In order to clarify those two parts, the images of the disc with complete and partial coating were labeled as $\alpha$ and $\beta$, respectively (Fig. 7(a)). It should be noted that both $\alpha$ and $\beta$ zones were representative regions in the wear track (Fig. S6). The color of the $\alpha$ region was a little bit darker than that of the $\beta$ zone and a clear boundary can be observed between these two areas. Besides, the topography of the $\alpha$ zone was relatively smooth in comparison with that of the $\beta$ zone (Fig. $7($ b)), indicating the formation of the solid lubricating layer. In addition, Fig. 7(c) displayed a random distribution of pores at the $\alpha$ zone, which could be generated by the released gas. This phenomenon implied that the gas release occurred at elevated temperature due to the graphite oxidation, consistent with the observed mass loss of the prepared coating. More importantly, graphite was not noticeably detected in the $\alpha$ zone, while it was clear to observe sheet-like graphite in the $\beta$ zone where the top surface of the coating was partially peeled off as signified by the yellow arrows under a higher magnification mode (Fig. 7(d)), suggesting the protective effect of the coating on the graphite. Besides the marked sheet-like graphite, the fusion of the reactants at high temperature occurred at both $\alpha$ and $\beta$ zones as denoted by the yellow frames (Fig. 7(d)), which made the amorphous $\mathrm{SiO}_{2}$ and $\mathrm{Al}\left(\mathrm{H}_{2} \mathrm{PO}_{4}\right)_{3}$ binder indistinguishable from each other and could lead to a formation of tight layers as indicated by the smooth surface of $\alpha$ zone. The SEM images clearly illustrate the formed solid lubricating coating could inhibit the disc surface from being exposed throughout the test, congruous with the observed excellent lubricating and anti-wear properties of the solid lubricating coating under the harsh experiment.

Thus, it is speculated that the layers formed by the fused $\mathrm{SiO}_{2}$ and $\mathrm{Al}\left(\mathrm{H}_{2} \mathrm{PO}_{4}\right)_{3}$ binder at high temperature would cover the solid lubricant graphite so that the graphite would be isolated and protected from being oxidized, which led to the excellent high-temperature lubricating performance via the aforementioned synergistic effect.

Moreover, the EDS mapping probe was employed to evaluate the distribution of the elements in the tribofilm surface after the friction tests at different

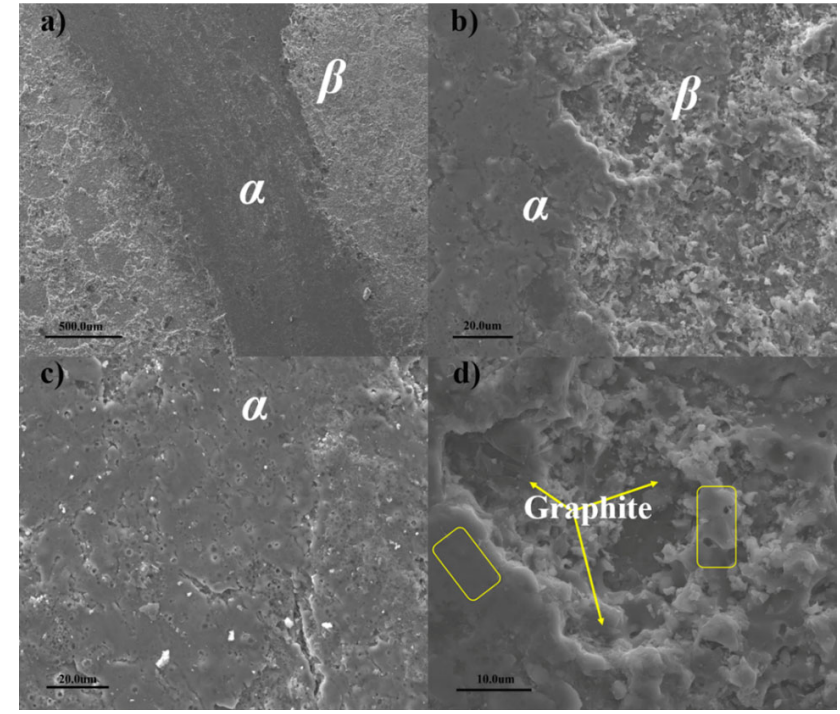

Fig. 7 SEM images of the wear track obtained from different lubricating regions after the friction test. (a) SEM image of regions with complete and partial coating labelled by $\alpha$ and $\beta$, respectively. (b) High magnified SEM image of $\alpha$ and $\beta$ zones. (c) SEM image showing the surface topography of the $\alpha$ zone. (d) SEM image demonstrating details of the $\beta$ zone in the lubricating coating after the friction test.

high temperatures (Figs. 8, S7, and S8). It was obviously seen that $\mathrm{Si}, \mathrm{Al}, \mathrm{P}$, and $\mathrm{O}$ were uniformly distributed in both $\alpha$ and $\beta$ zones after all friction tests, as denoted by the uniform colors across the regions. However, the situation was different for the $C$ element even for the same tribofilm surface. A large amount of $C$ could be observed in the $\beta$ zone, whereas $C$ was only observed in the $\alpha$ area with cracks. Therefore, it was proposed that the disappearance of the graphite on the coating surface was due to the graphite oxidation during the high-temperature friction process, while the interior graphite was preserved due to the protection from the formed solid lubricating coating during the friction test, well agreeing on the above discussion. In comparison with the $\mathrm{C}$ distribution after different tests, it is clear that more $\mathrm{C}$ remained after $700 / 800{ }^{\circ} \mathrm{C}$ tests, which was congruous with the observed phenomenon that the wear tracks of samples after $700 / 800{ }^{\circ} \mathrm{C}$ tests displayed more bight metallic luster.

Complementary to the surface information about the elemental distribution, the cross-section part of the coating with the wear track after the hightemperature friction test was probed by SEM/EDS to evaluate the interior part of the lubricating coating. 
Bearing in mind that the top surface of the coating fell off during this SEM sample preparation process, the area used for preparing the cross-section sample was actually the $\beta$ zone. The microtopography of the cross-section and the corresponding elemental distribution were shown in Fig. 9. It is observed that the lubricating coating was well bonded to the substrate, consistent with the above description, and had a thickness of around $10 \mu \mathrm{m}$. In addition, the element $C$ could be well observed inside the coating layer with almost homogeneous distribution, consistent with the above analysis, and $\mathrm{Si}, \mathrm{Al}, \mathrm{P}$, and $\mathrm{O}$ all distributed uniformly inside the coating. Given the falling off of the coating surface, it was impossible to observe the separation of the $C$ distribution between the top surface and the interior. Based on the elemental information at the surface and interior of the coating, hence, $\mathrm{C}$ predominantly existed inside the coating, while $\mathrm{Si}, \mathrm{Al}, \mathrm{P}$, and $\mathrm{O}$ were distributed uniformly across the coating surface and interior.

In terms of the excellent lubricant behavior displayed by the solid lubricating coating at high temperature, the proposed mechanism is as follows: $\mathrm{SiO}_{2}$ and $\mathrm{Al}\left(\mathrm{H}_{2} \mathrm{PO}_{4}\right)_{3}$ would fuse to form a layer at the surface of the solid lubricating coating at high temperature during the friction test and the graphite at the surface would be oxidized and lost in the form of gases. Then the formed layer would protect the interior graphite from being oxidized again, which leads to the preservation of the graphite and subsequently the superior lubricating performance at high temperature even under the air atmosphere. With that, the tribological performance of the prepared coating is much better relative to the similar type of coatings such as graphenemodified WC-12Co [45] and carbon fiber reinforced $\mathrm{Li}_{2} \mathrm{O}-\mathrm{Al}_{2} \mathrm{O}_{3}-4 \mathrm{SiO}_{2}$ composites [46], and better than or at least comparable with many other high-temperature lubricating coatings that have been summarized in [7].
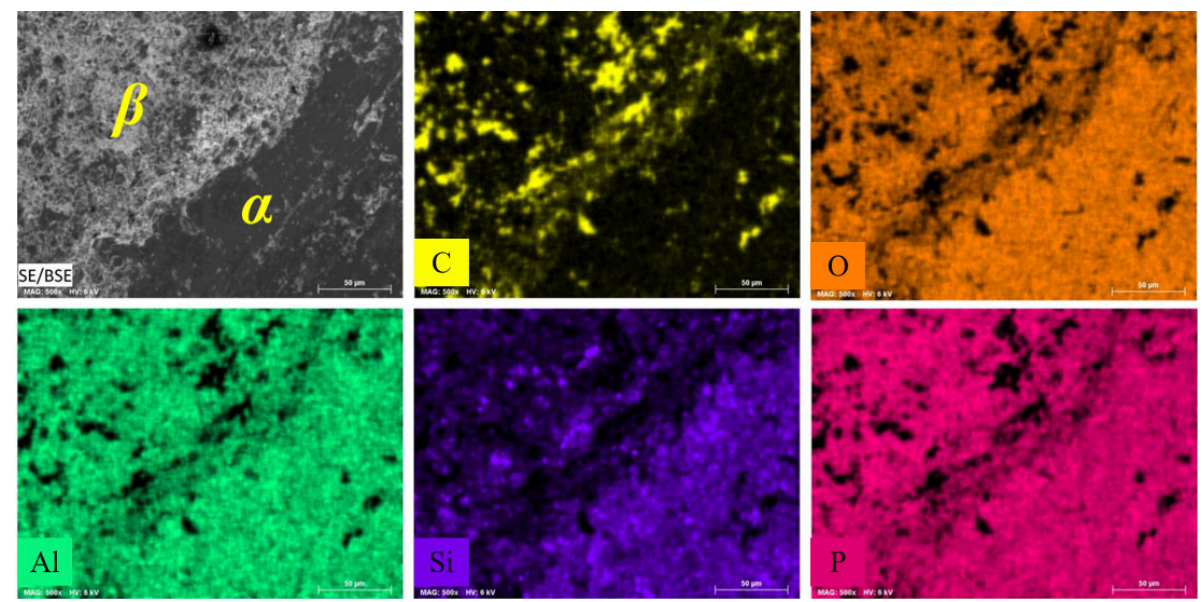

Fig. 8 EDS mapping showing the surface elemental distribution of $\alpha$ and $\beta$ zones in the lubricating coating after the friction test at $900{ }^{\circ} \mathrm{C}$.
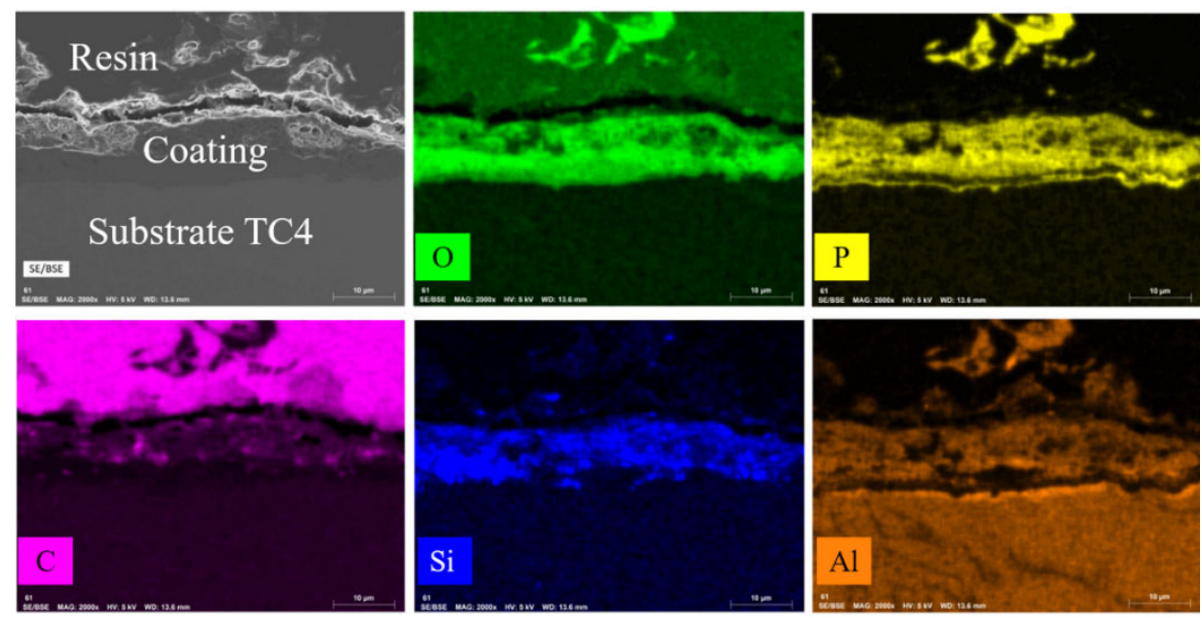

Fig. 9 SEM images and elemental distribution of the cross-section of the coating in the wear track. 


\section{Conclusions}

In summary, the present work demonstrates an eco-friendly graphite-based solid lubricating coating which was successfully prepared using a readily achievable method by an appropriate mixture of the amorphous $\mathrm{SiO}_{2}$, solid lubricant graphite, and $\mathrm{Al}\left(\mathrm{H}_{2} \mathrm{PO}_{4}\right)_{3}$ binder. This solid lubricating coating displayed a stable adhesion to the substrate and a superior lubricant performance with ultralow COF of about 0.05 at high temperature under the air atmosphere regardless of the operational sliding speed. In addition, there was no observed wear scar in the metal substrate due to the uniform coverage of the coating on the disc surface during the friction test process. The existence of the graphite in the sample after the friction test based on the XRD and Raman data was responsible for the excellent tribological performance. The comparative experiment demonstrated a critical role of $\mathrm{SiO}_{2}$ in protecting graphite from being oxidized and lost in the form of $\mathrm{CO}_{2}$ gas. This protective effect was further supported by the small mass loss of the coating during the thermogravimetric process. The morphology and elemental distribution of the wear track illustrated that the carbon almost uniformly existed inside the lubricating coating and $\mathrm{Si}, \mathrm{Al}, \mathrm{P}$, and $\mathrm{O}$ homogeneously resided across the surface and the bulk of the lubricating coating, moreover supporting the protective effect of the surface layer formed by the fused $\mathrm{SiO}_{2}$ and $\mathrm{Al}\left(\mathrm{H}_{2} \mathrm{PO}_{4}\right)_{3}$ at high temperature for the graphite. Overall, the synergistic effect of the protective layer and the lubricant graphite enables the superior lubricating performance exhibited by the solid lubricating coating at high temperature. This work broadens the applications of graphite-based coating at the elevated temperature under the air atmosphere and further offers an insight into designing the high-temperature solid lubricant.

\section{Acknowledgements}

The work is financially supported by the National Key Research and Development Program (No. 2018 YFB2002204) and the National Natural Science Foundation of China (Grant Nos. 51925506 and
$51527901)$.

Electronic Supplementary Material Supplementary material is available in the online version of this article at https://doi.org/10.1007/s40544-020-0456-2.

Open Access This article is licensed under a Creative Commons Attribution 4.0 International License, which permits use, sharing, adaptation, distribution and reproduction in any medium or format, as long as you give appropriate credit to the original author(s) and the source, provide a link to the Creative Commons licence, and indicate if changes were made.

The images or other third party material in this article are included in the article's Creative Commons licence, unless indicated otherwise in a credit line to the material. If material is not included in the article's Creative Commons licence and your intended use is not permitted by statutory regulation or exceeds the permitted use, you will need to obtain permission directly from the copyright holder.

To view a copy of this licence, visit http://creativecommons.org/licenses/by/4.0/.

\section{References}

[1] Tomala A, Hernandez S, Rodriguez Ripoll M, Badisch E, Prakash B. Tribological performance of some solid lubricants for hot forming through laboratory simulative tests. Tribol Int 74: 164-173 (2014)

[2] Rao K P, Xie C L. A comparative study on the performance of boric acid with several conventional lubricants in metal forming processes. Tribol Int 39(7): 663-668 (2006)

[3] Dohda K, Boher C, Rezai-Aria F, Mahayotsanun N. Tribology in metal forming at elevated temperatures. Friction 3(1): 1-27 (2015)

[4] Sliney H E. High Temperature Solid Lubricants: When and Where to Use Them. 1973.

[5] Wang L, Tieu A K, Cui S G, Deng G Y, Wang P, Zhu H $\mathrm{T}$, Yang J. Lubrication mechanism of sodium metasilicate at elevated temperatures through tribo-interface observation. Tribol Int 142: 105972 (2020)

[6] Allam I M. Solid lubricants for applications at elevated temperatures. J Mater Sci 26(15): 3977-3984 (1991)

[7] Meng Y G, Xu J, Jin Z M, Prakash B, Hu Y Z. A review of recent advances in tribology. Friction 8(2): 221-300 (2020)

[8] Sliney H E. Solid lubricant materials for high temperatures 
-A review. Tribol Int 15(5): 303-315 (1982)

[9] Scharf T W, Prasad S V. Solid lubricants: A review. $J$ Mater Sci 48(2): 511-531 (2013)

[10] Lavrakas V. Textbook errors: guest column. XII: the lubricating properties of graphite. J Chem Educ 34(5): 240 (1957)

[11] Wang L, Tieu A K, Zhu H T, Deng G Y, Hai G J, Wang J, Yang J. The effect of expanded graphite with sodium metasilicate as lubricant at high temperature. Carbon 159: 345-356 (2020)

[12] Liu Z J, Guo Q G, Shi J L, Zhai G T, Liu L. Graphite blocks with high thermal conductivity derived from natural graphite flake. Carbon 46(3): 414-421 (2008)

[13] Zhou Y P, Dong Y J, Yin H Q, Li Z C, Yan R, Li D B, Gu Z W, Sun X M, Shi L, Zhang Z Y. Characterizing thermal-oxidation behaviors of nuclear graphite by combining $\mathrm{O}_{2}$ supply and micro surface area of graphite. Sci Rep 8(1): 13400 (2018)

[14] Theodosiou A, Jones A N, Marsden B J. Thermal oxidation of nuclear graphite: A large scale waste treatment option. PLoS One 12(8): e0182860 (2017)

[15] Jiang W, Nadeau G, Zaghib K, Kinoshita K. Thermal analysis of the oxidation of natural graphite - Effect of particle size. Thermochim Acta 351(1-2): 85-93 (2000)

[16] Hanaor D, Michelazzi M, Chenu J, Leonelli C, Sorrell $\mathrm{C}$ C. The effects of firing conditions on the properties of electrophoretically deposited titanium dioxide films on graphite substrates. J Eur Ceram Soc 31(15): 2877-2885 (2011)

[17] Luo X W, Jean-Charles R, Yu S Y. Effect of temperature on graphite oxidation behavior. Nucl Eng Des 227(3): 273-280 (2004)

[18] Kane J J, Contescu C I, Smith R E, Strydom G, Windes $\mathrm{W}$ E. Understanding the reaction of nuclear graphite with molecular oxygen: kinetics, transport, and structural evolution. J Nucl Mater 493: 343-367 (2017)

[19] Semchenko G D, Shuteeva I Y, Slepchenko O N, Angolenko L A. Protection of graphite and graphitecontaining materials from oxidation. Refract Ind Ceram 46(4): 260-267 (2005)

[20] Tomala A, Ripoll M R, Badisch E. Tool-solid lubricantworkpiece interactions in high temperatures applications. Procedia Eng 68: 626-633 (2013)

[21] Kumar U, Mishra A K, Ohdar R. Hot forging lubricants. Int J Mech Eng Rob Res 3(4): 155-163 (2014)

[22] Kargin S, Artyukh V, Ignatovich I, Dikareva V. Development and efficiency assessment of process lubrication for hot forging. IOP Conf Ser Earth Environ Sci 90: 012190 (2017)

[23] Jayaseelan V, Kalaichelvan K, Ananth S V. Lubrication effect on friction factor of AA6063 in forward extrusion process. Procedia Eng 97: 166-171 (2014)

[24] Zmij V I, Rudenky S G, Kunchenko V V, Timofeeva E V,
Kunchenko Y V, Azhazha R V. Heat-resistant complex coatings on carbon materials. Voprosy Atomnoj Nauki $i$ Techniki 90(2): 158-161 (2014)

[25] Criscione J M, Mercuri R A, Schram E P, Smith A W, Volk H F. High Temperature Protective Coatings for Graphite. Air Force Materials Laboratory, 1965.

[26] Nechepurenko A, Samuni S. Oxidation protection of graphite by BN coatings. J Solid State Chem 154(1): 162-164 (2000)

[27] Zhao J, Liu L, Guo Q G, Shi J L, Zhai G T. Oxidation protective behavior of $\mathrm{SiC} / \mathrm{Si}-\mathrm{MoSi}_{2}$ coating for different graphite matrix. Mater Lett 60(16): 1964-1967 (2006)

[28] Kim T, Singh D, Singh M. Enhancement of oxidation resistance of graphite foams by polymer derived-silicon carbide coating for concentrated solar power applications. Energy Procedia 69: 900-906 (2015)

[29] Zhou P, Li Z Q, Zhao H S, Zhang K H, Liu X X, Liu B. $\mathrm{SiC} / \mathrm{SiO}_{2}$ coating on matrix graphite spheres of HTR fuel element produced by a two-step pack cementation/ high-temperature oxidation process. Mater Sci Forum 852: 952-958 (2016)

[30] Zmij V I, Rudenkyi S G, Shepelev A G. Complex protective coatings for graphite and carbon-carbon composite materials. Mater Sci Appl 6(10): 879-888 (2015)

[31] Jiang Y, Ren Q X, Ru H Q, Mao Z L, Xu H B. Oxidation protection of graphite materials by single-phase ultra-high temperature boride modified monolayer Si-SiC coating. Ceram Int 45(1): 539-549 (2019)

[32] Yang X, Huang Q Z, Su Z A, Chang X, Chai L Y, Liu C $X$, Xue L, Huang D. Resistance to oxidation and ablation of $\mathrm{SiC}$ coating on graphite prepared by chemical vapor reaction. Corros Sci 75: 16-27 (2013)

[33] Park S J, Seo M K. The effects of $\mathrm{MoSi}_{2}$ on the oxidation behavior of carbon/carbon composites. Carbon 39(8): 1229-1235 (2001)

[34] Jiang Y, Ye C C, Ru H Q, Wang W, Zhang C P, Yue X Y. Oxidation protective $\mathrm{MoSi}_{2}-\mathrm{SiC}-\mathrm{Si}$ coating for graphite materials prepared by slurry dipping and vapor silicon infiltration. Ceram Int 44(5): 5171-5178 (2018)

[35] Ferrari A C, Meyer J C, Scardaci V, Casiraghi C, Lazzeri M, Mauri F, Piscanec S, Jiang D, Novoselov K $\mathrm{S}$, Roth S, et al. Raman spectrum of graphene and graphene layers. Phys Rev Lett 97(18): 187401 (2006)

[36] Tuinstra F, Koenig J L. Raman spectrum of graphite. J Chem Phys 53(3): 1126-1130 (1970)

[37] Huang K, Bi K, Liang C, Lin S, Wang W J, Yang T Z, Liu J, Zhang R, Fan D Y, Wang Y G, et al. Graphite carbon-supported $\mathrm{Mo}_{2} \mathrm{C}$ nanocomposites by a single-step solid state reaction for electrochemical oxygen reduction. PLoS One 10(9): e0138330 (2015)

[38] Pimenta M A, Dresselhaus G, Dresselhaus M S, Cancado L G, Jorio A, Saito R. Studying disorder in graphite-based systems by raman spectroscopy. Phys 
Chem Chem Phys 9(11): 1276-1290 (2007)

[39] Coenen K, Gallucci F, Mezari B, Hensen E, van Sint Annaland M. An in-situ IR study on the adsorption of $\mathrm{CO}_{2}$ and $\mathrm{H}_{2} \mathrm{O}$ on hydrotalcites. $J \mathrm{CO}_{2}$ Util 24: 228-239 (2018)

[40] Pei Y C, Xiao C X, Goh T W, Zhang Q H, Goes S, Sun W J, Huang W Y. Tuning surface properties of aminofunctionalized silica for metal nanoparticle loading: the vital role of an annealing process. Surf Sci 648: 299-306 (2016)

[41] Sun Q. The raman $\mathrm{OH}$ stretching bands of liquid water. Vib Spectrosc 51(2): 213-217 (2009)

[42] Izairi N, Ajredini F, Shehabi M. Investigation of pollutant gases with molecular absorption spectroscopy. Physica Macedonica 99-105 (2011)

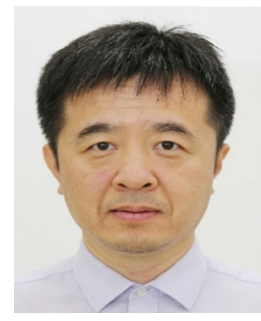

Chenhui ZHANG. He received his Ph.D. degree in mechanical engineering from Tsinghua University, Beijing, China in 2004. Since then, he has been working at the State Key Laboratory of Tribology at Tsinghua University. From

February 2011 to August 2011, he was invited to Luleå

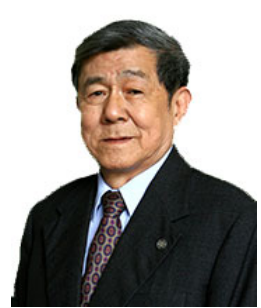

Shizhu WEN. He received his B.E. degree in the Department of Precision Instruments and Mechanology, Tsinghua University, Beijing, China, in 1955. He went to Imperial College London in the UK as a visiting scholar between 1979 and 1981. Prof. Shizhu Wen is an academician of the Chinese Academy of Sciences and the honorary director of the State Key Laboratory of Tribology. He had received 19 national or ministerial prizes

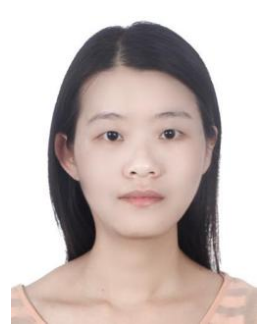

Wenjuan HUAI. She received the B.S. degree in chemistry from Hebei Normal University in 2011, and her M.S. degree was graduated from the University of Chinese Academy of Sciences in 2014. After that,
[43] Larkin P. Infrared and Raman Spectroscopy. Amsterdam (the Netherlands): Elsevier, 2011

[44] Garcia-hernandez D A, Cataldo F, Manchado A. About the iron carbonyl complex with $\mathrm{C}_{60}$ and $\mathrm{C}_{70}$ fullerene: $\left[\mathrm{Fe}(\mathrm{CO})_{4}\left(\eta^{2} \mathrm{C}_{60}\right)\right]$ and $\left[\mathrm{Fe}(\mathrm{CO})_{4}\left(\eta^{2} \mathrm{C}_{70}\right)\right]$. Fuller Nanotub Car N 24(3): 225-233 (2016)

[45] Tian H L, Wang C L, Guo M Q, Cui Y J, Gao J G, Tang $\mathrm{Z} \mathrm{H}$. Microstructures and high-temperature self-lubricating wear-resistance mechanisms of graphene-modified WC-12Co coatings. Friction 9: 315-331 (2021)

[46] Ma H B, Wu X, Xia L, Huang L N, Xiong L, Yang H, Zhong B, Zhang T, Yang Z W, Gao F, et al. Friction and wear behavior of carbon fiber reinforced lithium aluminosilicate composites sliding against GCr15 steel. Friction 8(6): 1063-1072 (2020)

University of Technology in Sweden as a visiting scholar. He was also invited to the Weizmann Institute of Science in Israel as a visiting scientist from February 2012 to January 2013. Currently, he is a professor at Tsinghua University. His research interests are nanocoating technology and applications, the theory of water-based lubrication, and the mechanism of superlubricity.

for his distinguished research achievements, including the second prize in the National Natural Science Awards, the third prize in the National Technology Invention Awards, 2004 award for Teaching \& Research of Tsinghua University, and the Science and Technology Achievement Award of the Ho Leung and Ho Lee Foundation in 2002. His research interests are elastohydrodynamic lubrication, thin-film lubrication, the mechanism of friction control and wear, nanotribology, and micro-machine design.

she worked as a research assistant in the State Key Laboratory of Tribology at Tsinghua University. Currently, she is a Ph.D. candidate in the State Key Laboratory of Tribology at Tsinghua University. Her research focuses on the high-temperature lubrication for the metal forming process. 